\title{
Review on the Research of Dynamic Competition Theory
}

\author{
Jianbin Zhang, Dan Gao \\ Management School, Jinan University, Guangzhou, China \\ Email: 447205670@qq.com
}

Received 9 October 2014; revised 9 November 2014; accepted 8 December 2014

Academic Editor: Charbel J. C. Jabbour, UNESP-Sao Paulo State University, Bauru, Brazil

Copyright (C) 2014 by authors and Scientific Research Publishing Inc.

This work is licensed under the Creative Commons Attribution International License (CC BY).

http://creativecommons.org/licenses/by/4.0/

(c) (i) Open Access

\begin{abstract}
In the 1980s, dynamic competition theory originated in the field of strategic management abroad. It focused on the behaviors of attacks and counterattacks interaction among the enterprises. But Chinese researchers paid attention to the dynamic research a long time later. On the basis of the existing research, this article summarized the theoretical background research object and the research methods, and analyzed the limitations and future research direction of dynamic competition.
\end{abstract}

\section{Keywords}

Dynamic Competitive, Action/Response, Competitive Interaction

\section{Introduction}

Study on dynamic competition began in the early 80s. The research of Edwards on confrontation between enterprises can be traced back to the mid 50s. They proposed the opinion that we could explore the competitive strategy from the perspective of enterprise competitive behavior. In the late 90s, Chinese scholars began to introduce the methods and conclusions of dynamic competition [1]-[3]. In the western literature, it was generally called dynamic competition. The object of study generally refers to specific behaviors in the process of enterprises competition.

In the 1980s, MacMillan, McCaffrey and Van Wijk (1985) provided a reference for empirical research of dynamic competition in response to the innovation behavior of a bank of small sample study [4]. Bettis and Weeks (1987) studied the stock market for Polaroid and Kodak imaging products in a competitive field of interactive response [5]; Smith, Grimm, Chen, and Gannon (1989) used the data of high-tech enterprises, researching on attack behavior features which could arise rapid counterattack [6]. 
In the 90's, Chen, Smith and Grimm (1992) took the competition behaviors of American aviation industry as an example, studying on the relationship between the company competitive response and competitive behavior features. They found different competitive action traits combination including competitive influence, attack strength, executive condition, and action which had different effects on response rate, and time competitors [7]; taking software producers as the object of the research, Young, Smith and Grimm (1996) found that if the enterprises could attack more fiercely and frequently, it could gain better performance [8]; Xie Hongming and Lan Hailin (2003) carried out an empirical research on dynamic competition of the Chinese color TV market [2].

This article aims to summarize the background, research conclusions, and possible development direction of the dynamic competition theory in the future.

\section{The Theory of Dynamic Competition Background}

Dynamic competition theory from Schumpeter's (1950) "creative destruction" [9] theory is used to explain the dynamic market, every enterprise how to use in a dynamic market for action and response to pursue market opportunities. May also be defined as the process of experience in competitive action and response, the company decided how the ups and downs.

"Austria school" to the market competition as a dynamic process, rather than a static market situation, for profit action will break the stable status, so the market will never reach equilibrium, except in the absence of competition. For an explanation of the "destruction", the Austria school put forward the concept of "entrepreneurial discovery", that is when the market opportunities have emerged, the enterprise can successfully guide and the allocation of resources, to meet customer demand action. From the dynamic point of view to explain the competition, the scholars began to focus on the competition behavior of innovation, such as the first dynamic action or radical action [10].

Play an important role in Schumpeter's "creative destruction" theory and the Austria school "entrepreneurial discovery" plays a very important role in the dynamic competitive field. Action is the core of the research unit of the two theories, starting from the two theories, the research of dynamic competition more and more scholars focus on the competitive supply and counter attack.

\section{The Basic Mode and Key Factors of Dynamic Competition}

\subsection{The Basic Mode}

Study on the key factors of dynamic competition is competition among enterprises, it will be the competition behavior understood as interactive competitive action and response [11]. The manufacturer's own relative competitive position for defensive or improvement, through the analysis of the market, integrate its own resources, to reduce the use of the product price, new product introduction and other ways to gain market share and additional benefits. Obviously, this process may be by the market of other manufacturers counterattack, obtain additional benefits, to defend the attacker to occupy the market share. Through the cycle back and forth such attack and counterattack, to allow the market to achieve a temporary equilibrium process. According to the behavior of the process of dynamic competition, can be obtained as shown in Figure 1 [11].

\subsection{The Key Factors of Dynamic Competition}

Competitive interaction: Competition among enterprises is the key to the research of dynamic competition among enterprises, usually will process this attack and response is called competitive interaction. As shown in Figure 2 [7].

Competitors and competitive action: Competitors generally refers to the initiator competition, it is the primary sponsor attacks, is also the result of the action of beneficiaries [12]. How the dynamic competition theories concerned competitor characteristics influence the attack action decision. Different research to find the organization characteristics, there are three kinds of recessive and key influence strategic action that is Awareness-Motivation-Capability, AMC [13].

Awareness: How firms cognitive competitors, the driving force and competitive environment of the overall intra industry competition. To observe the influence to the enterprise to understand the result of the action, so it is very important to [13].

Motivation: Associated with gains or losses can be felt, actions taken or not taken action depends on the gain from action possible advantage or no action possible loss. 


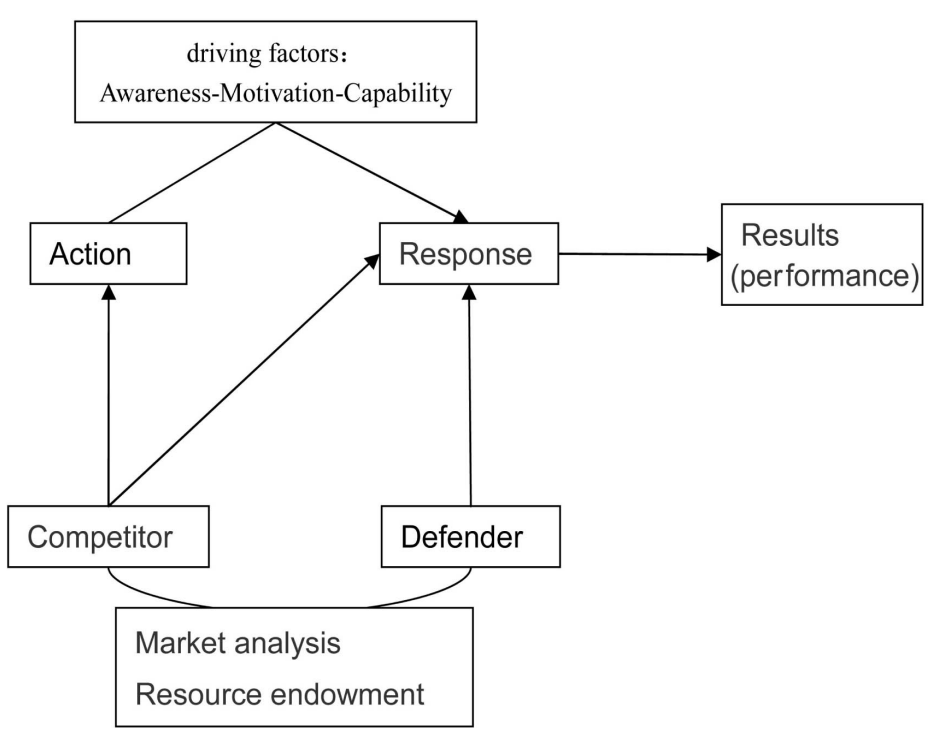

Figure 1. Dynamic competition model.

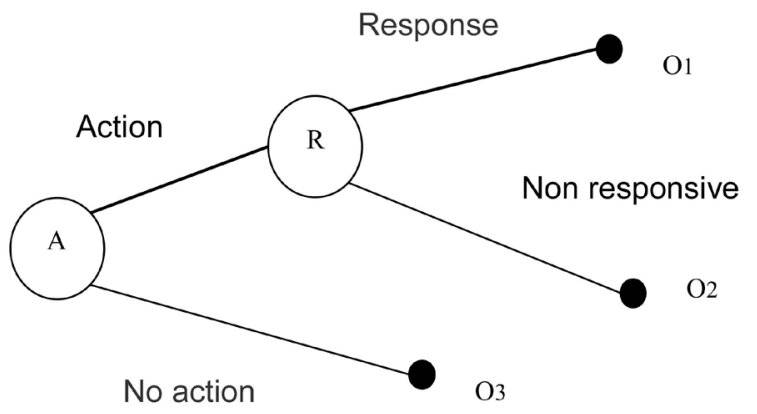

Figure 2. Game decision tree. Game decision tree is shown, when firms a planning competitive action, competitor $r$ there are two types of action: response $(\mathrm{O} 1)$ or no response $(\mathrm{O} 2)$. Usually will process this attack and response is called competitive interaction.

Capability: Action is the result of the resource allocation process and enterprise decision. When the enterprise to take action, the rest of the organizational resources (the flow of financial resources), and characteristics of top management team will affect the attack and counter thinking form or execution, so the ability to organize action execution is important influence [13].

Competitive action is a basic concept of dynamic competition. For the performance of work or do new things in a new way. Smith, K.G., Grimm (1991) definition of competitive action as "manufacturers in order to enhance or defending the relative competitive position, instigated a certain cut can be clearly aware of the competitive behavior" [7], Chen, Smith, K.G. and Grimm (1992) summarizes the competitive action characteristics: competitive impact: a action against competitors affect or influence degree; attract intensity: the degree of influence of an action on a major competitor market; implementation requirement: the level of effort to take action manufacturers perform the action of inputs required; type of action: strategic or tactical. Confirm the competitive action traits will affect different for defense of competition response has different effects [7].

Competitive response: When the competitive action won the excess earnings or the attack effect to rival station, competitors will produce a response to its competitive action. Smith, K.G., Grimm (1991) defined competitive response to "manufacturers in order to defense or improve their relative competitive position, the one that can be observed and can be identified in response to action" [7]. Chen, Smith, K.G. and Grimm (1992) from "a potential response will affect the competitive action again to create and sustain competitive advantage on the effect of" starting, summarizes the competitive response traits:

Number of responses: the number of competitive response caused by the manufacturer. 
Response lag: that competitive action occurred to the defender execute the response time of action [7].

Characteristics of competitive response are vital to take competitive action by competitors, can predict the competitive action of competitors and success.

Competitive interaction results: To achieve the desired results through competition interaction, the general use of performance to assess the competitive interaction effect. Including the change of market share, sales growth to increase shareholder returns and other financial variables measure of profitability. The empirical study shows that attack, counterattack, combination of actions and action sequences characteristics will affect the performance of the organization (Smith, 1991; Smith and Young, 1996; Ferrier, 1999; Miller and Chen, 1995) [12] [14].

Relationship between competitive action and response: Dynamic competition theory is in a dynamic environment, interaction between firms competitive focus. Companies take the lead in action after the success, will inevitably lead to competitors to imitate or counter (Schumpeter, 1950). Through a large number of empirical studies has been consistent conclusion, namely the use of the characteristic of enterprise forecast attack can competitor on the counterattack. Competitive action can predict the number and frequency response. Competitive action can also predict the response speed. Different types of competitive actions have different influence on the response speed (Smith, 1992; Chen, 1992) [15] [16].

\section{Empirical Research Method of Dynamic Competition}

\subsection{Field Research Method}

Based on the small sample enterprises and meticulous observation and monitoring, identification of the enterprise of attack and counterattack action, thus the relationship between organizational characteristics and competitive action verification. The earliest studies including Bettis and Weeks (1987) studied the stock market on the Polaroid and Kodak competitive interaction in imaging products in the fields of reaction [17].

\subsection{Structured Content Analysis Method}

Structured content analysis is based on a formal decoding procedure, a tool such as newspapers, magazines and other published data secondary data analysis. Enables researchers to develop a large sample, analyze the competition action from more data. Chen Smith, Ken's and Grimm (1992) by the method of competitive behavior of American aviation industry manufacturers to do the research [17].

\section{Analysis of Dynamic Competition}

The core research of dynamic competition theory is an important competitive element around the strategic management research, free from the traditional static analysis, the dynamic process of inter enterprise competition behavior as the research object, to in-depth understanding of enterprise competition behavior of competition must be changing trend and the influence to carry on the analysis, the study also shows that the enterprise competitive advantage has not can be maintained, to maintain the competitive advantage they need to constantly create new advantages.

Dynamic competitive enterprises through the competitive interaction among enterprises can change the allocation of resources and industrial structure has. Due to the difference of the degree of response to different types of competitive behavior, is advantageous for the enterprise to subsequent predictions for the competitors in the competitive interaction behavior, the promotion enterprise competitive advantage [18].

Combining with the important concepts in different fields and theoretical research around the manufacturer will be a series of competitive behavior into research and development of dynamic competition, but also brought some new theory system, made a great contribution to such as first mover advantage, irreversibility, multipoint competition and competition network, super strong competition for strategic management theory to further improve the. At the same time analysis method based on the level of action, so that the dynamic competition theory to establish a detailed analysis of the structure to compensate for the lack of competition orientation and group orientation, strategic researchers and practitioners from the basic perspective, to understand the competition and effectively participate in the competition [19].

Dynamic competition theory also has certain limitation, pay attention to the research on the content of the manufacturer in competition market level, but between enterprises compete not only exist in the market also ex- 
ist with deeper. Such as the value chain of enterprises, organizational ability, human resources and other aspects. So for the competition behavior of attention should expand the range and depth of. At present the research methods of scholars use basic including early field research and content analysis method. But the two methods all have limitations, the field study is confined to the study and review of small sample, validity, effectiveness is not strong. Structured content analysis using secondary data, because of the competition behavior is not easy to define and measure, the credibility of the data have some limitations, the research methods need to be further perfected. Scholars in the research field of the current are too single, limit the scope to study the dynamic competition theory. Need to exaggerate the new industry, enhance the applicable scope of the theory.

\section{Conclusion}

Many foreign scholars believe that the research of dynamic competition has a certain relationship with Chinese Sun Tzu art of war. China is still in the initial stage of development at present, so the research of dynamic competition in china will make sense. If we can combine the dynamic competitive strategy theory and the development status of China, it will contribute to the competitiveness and management level of Chinese enterprises.

\section{References}

[1] Chen, X. (2000) Dynamic Competitive Strategy and Chinese Enterprises. Chemical Technical Economy, 1, 36-39.

[2] Lan, H.L. and Huang, Z.F. (2000) The Attack and Counter-Dynamic Competition from TV "Price War". Enterprise Management, 3, 27-29.

[3] Lan, H.L. (2001) World Class Enterprise Strategic Management of Chinese Enterprises Research. Enterprise Management Press, China.

[4] Van Wijk, M. (1985) Competitors’ Responses to Easily Imitated New Products-Exploring Commercial Banking Product Introductions. Strategic Management Journal, 6, 75-86. http://dx.doi.org/10.1002/smj.4250060106

[5] Bettis, R.A. and Weeks, D. (1987) Financial Returns and Strategic Interaction: The Case of Instant Photography. Strategic Management Journal, 8, 549-563. http://dx.doi.org/10.1002/smj.4250080605

[6] Smith, K.G., Grimm, C.M., Chen, M.-J. and Gannon, M.J. (1989) Predictors of Response Time to Competitive Strategic Actions: Preliminary Theory and Evidence. Journal of Business Research, 18, 245-258. http://dx.doi.org/10.1016/0148-2963(89)90048-9

[7] Ming-Jar, C., Smith, K.G. and Grimm, C.M. (1992) Action Characteristics as Predictors of Competitive Responses. Management Science, 38, 439-455. http://dx.doi.org/10.1287/mnsc.38.3.439

[8] Smith, Y. (1996) “Austrian” and Industrial Organization Perspectives on Firm-Level Competitive Activity and Performance. Organization Science, 7, 243-254. http://dx.doi.org/10.1287/orsc.7.3.243

[9] Liu, B.M., Sun, J.G. and Tan, R.H. (2011) Innovation Theory Overview. Science and Technology Management Research Damage, 24, 9-12.

[10] Chen, M. (2007) Competitive Dynamics Research: An Insider’s Odyssey. Asia Pacific Journal of Management, 26, 5-25. http://dx.doi.org/10.1007/s10490-008-9110-7

[11] Smith, K.G., Grimm, C.M., Gannon, M.J., et al. (1991) Organizational Information-Processing, Competitive Responses and Performance in the US Domestic Airline Industry. Academy of Management Journal, 34, 60-85. http://dx.doi.org/10.2307/256302

[12] Chen, M. and Macmillan, I.C. (1992) No Response and Delayed Response to Competitive Moves: The Roles of Competitor Dependence and Action Irreversibility. Academy of Management Journal, 35, 539-570. http://dx.doi.org/10.2307/256486

[13] Chen, M. (1996) Competitor Analysis and Interim Rivalry: Toward a Theoretical Integration. Academy of Management Review, 21, 100-134.

[14] Qin, J. and Wang, Y.J. (2008) Dynamic Competition: A Conceptual Framework and Research Proposals Reviewed. Journal of Xi' an Institute of Finance and Economics, 2, 83-87.

[15] Liu, Y. and Li, T. (2005) The Research of Enterprise Competition Behavior and the Theory of Dynamic Competition Environment. Journal of Information, 7, 64-66.

[16] Wu, H.S. (2007) The Development and the Dynamic Competitive Advantage Creation of Strategic Management Theory. Journal of Shogun University, 1, 128-131.

[17] Zhang, Y. and Chang, Y.S. (2008) The Research Perspective and Analysis of Dynamic Competition Theory Framework. The Productivity Research, 2, 11-12. 
[18] Xie, W.H. and Lan, H.L. (2001) Flexible Organization: Choice of Enterprise under the Condition of Dynamic Competition. The Soft Science, 3, 90-92.

[19] Xie, H.M., Lan, H.L., Ye, G.Y., et al. (2003) Dynamic Competition: An Empirical Study of China’s Main Color TV Enterprises. Management World, 4, 77-86. 
Scientific Research Publishing (SCIRP) is one of the largest Open Access journal publishers. It is currently publishing more than 200 open access, online, peer-reviewed journals covering a wide range of academic disciplines. SCIRP serves the worldwide academic communities and contributes to the progress and application of science with its publication.

Other selected journals from SCIRP are listed as below. Submit your manuscript to us via either submit@scirp.org or Online Submission Portal.
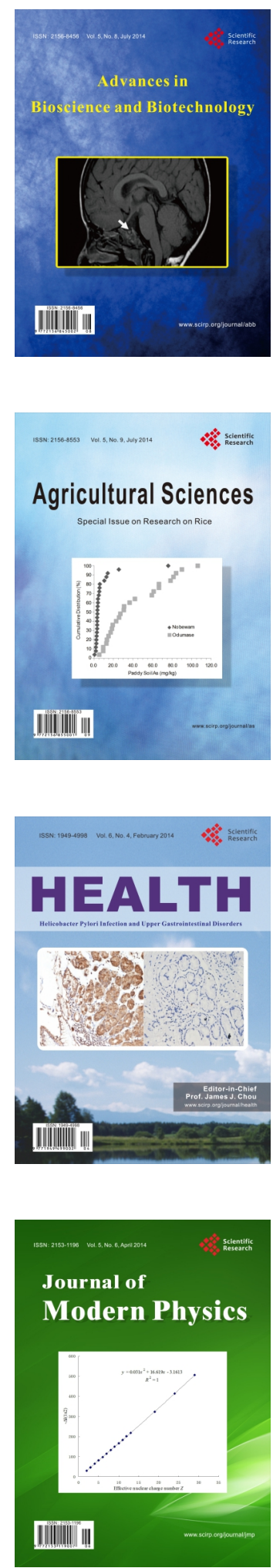
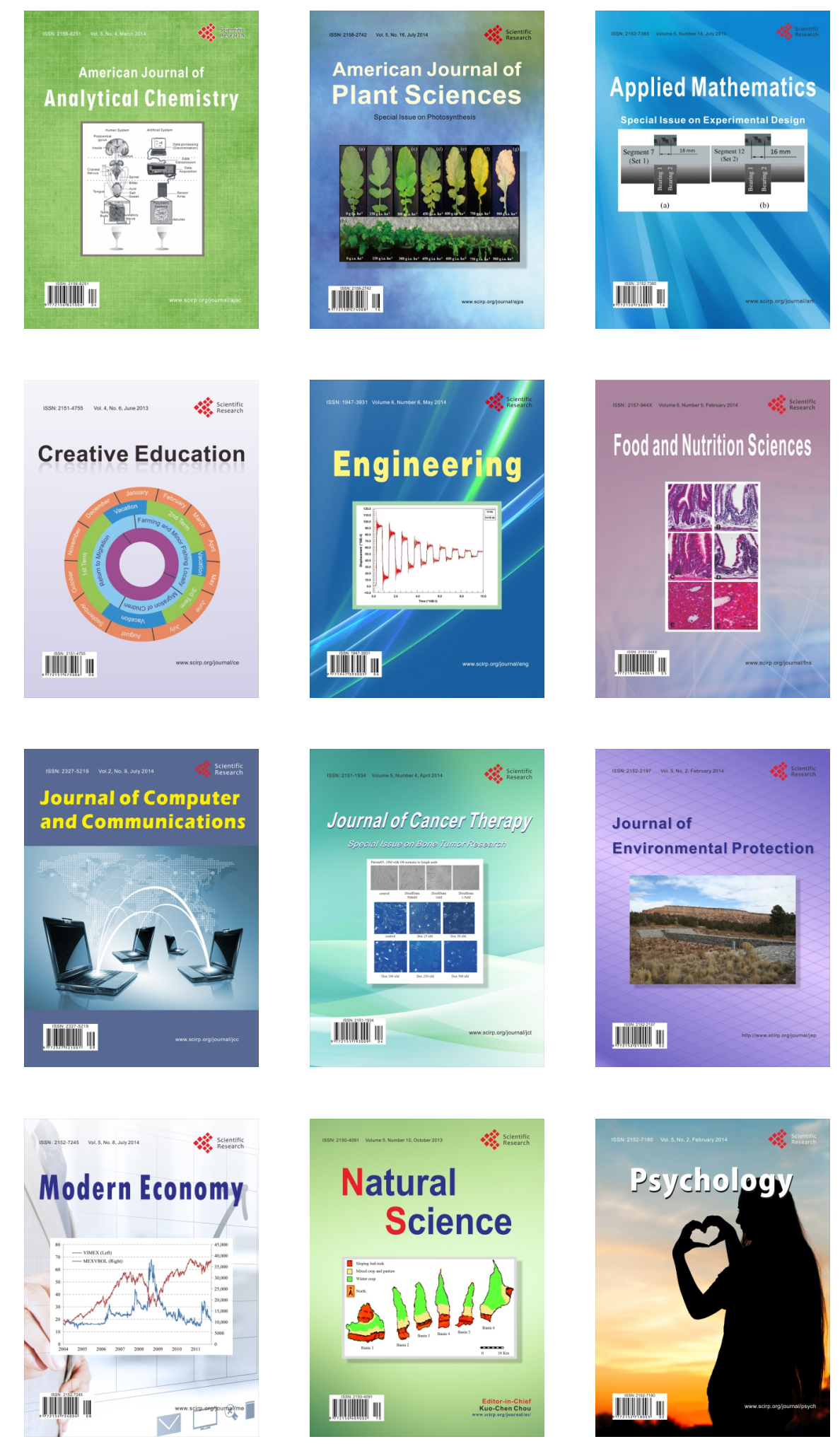